\title{
Los regadíos tradicionales del eje del río Turia. Inventario de los sistemas de riego y de los elementos catalogados del patrimonio hidráulico
}

\author{
José Vicente Aparicio Vayá, Emilio Iranzo García y Jorge Hermosilla \\ ESTEPA (Estudios del Territorio Paisaje y Patrimonio) Departament de Geografia. Universitat de València \\ j.vicente.aparicio@uv.es, emilio.iranzo-garcia@uv.es,jorge.hermosilla@uv.es
}

\begin{abstract}
Resumen El río Turia se origina en el término municipal de Teruel, tras la confluencia de los ríos Alfambra y Guadalaviar. Avena una amplia extensión de territorio a su paso por tierras turolenses, conquenses y valencianas. En su recorrido hasta su desembocadura en el mar Mediterráneo, en Valencia, da lugar a una miríada de vegas irrigadas con las acequias que de él derivan por medio de azudes. Canales a los que se vinculan una amplia variedad de elementos hidráulicos (partidores, acueductos, sifones...), que con el tiempo se han patrimonializado. El estudio ofrece una panorámica de una parte del trabajo de inventario y análisis que viene realizando, desde el año 1998, el grupo de investigación ESTEPA (Estudios del Territorio, Paisaje y Patrimonio) el cual abarca más del 50\% del ámbito de la cuenca hidrográfica del Júcar, a la cual se adscribe el río Turia. El objetivo de la comunicación es dar a conocer el inventario de los sistemas de regadío tradicionales y elementos del patrimonio del agua del eje fluvial del Turia catalogados, y efectuar una caracterización (análisis morfológico y funcional por unidad hidráulica) y clasificación tipológica. Este trabajo se sustenta en una infraestructura de datos espacial sobre el patrimonio hidráulico tradicional y los paisajes del agua, diseñada por la unidad de investigación. La investigación comprende la totalidad de los territorios irrigados con las aguas procedentes del cauce principal del río Turia. Se analizan tanto los sistemas de escaso recorrido longitudinal, vinculados a una unidad hidráulica menor (como por ejemplo alguno de los sistemas de riego del interior de la provincia de Valencia), como los de mayor envergadura (Huerta de Valencia), que abarcan una mayor superficie y diversas entidades locales.
\end{abstract}

Palabras clave: sistemas de regadío tradicionales, patrimonio del agua, río Turia.

\begin{abstract}
The Turia river starts at the town of Teruel, after the confluence of the rivers Alfambra and Guadalaviar. It supplies a large territory in the provinces of Teruel, Cuenca and Valencia. On its way to its mouth at the Mediterranean Sea, in Valencia, the river creates a set of meadows irrigated by a number of channels that collect water from the river. These irrigation systems are complemented by other hydraulic components (primers, aqueducts, siphons ...), which are considered cultural heritage. This study provides an overview of the work carried out since 1998, the research group ESTEPA (Studies Planning, Landscape and Heritage). The goal of communication is to present the inventory of traditional irrigation systems and water heritage elements of the Turia river; and to make a characterization (morphological and functional analysis by hydraulic area) and typological classification.
\end{abstract}

Keywords: traditional irrigation systems, water heritage, Turia River.

\section{Introducción}

El uso de las aguas a lo largo de la historia por los distintos grupos humanos que han habitado la cuenca del río Turia ha propiciado, en primer lugar, unos sustanciales cambios ambientales con claras manifestaciones paisajísticas; y en segundo lugar, una impronta cultural que se refleja en la organización territorial y social y en el rico patrimonio del agua. Los regadíos tradicionales constituyen todo un entramado cultural de gestión de los recursos hídricos y del suelo, que se manifiesta mediante las unidades paisajísticas de las huertas, las vegas y las riberas. Se trata de espacios que reúnen diversos valores, no siempre igualmente considerados. Hasta finales del siglo XX, las investigaciones se han concentrados o bien en los valores productivos de los regadíos o bien en los valores históricos. Pero las cuali- 
dades de los sistemas de riego tradicional no terminan aquí. Nuevos enfoques tratan de poner en valor las cualidades ambientales, paisajísticas y patrimoniales de estos espacios hidráulicos, en los que naturaleza y cultura se mantienen un frágil equilibrio. Efectivamente en los últimos veinte años se ha renovado el interés por el análisis de los sistemas de regadío tradicionales. Un interés que va más allá de la visión agronómica, especialmente ahora en un momento en que la agricultura tradicional experimenta una situación crítica y es cada vez más cuestionada. Así, a los trabajos previos de investigadores como Antonio López Gómez, Arthur Maass, Miquel Barceló, Vicenç Roselló, Roland Courtot, Pierre Guichard Joan Mateu, Antonio Gil, Antonio Gil y por supuesto de Thomas F. Glick entre muchos otros (Sanchis, Hermosilla e Iranzo, 2004) se incorporan bajo el enfoque paisajístico-patrimonial los trabajos de Jorge Hermosilla, de Rafael Mata, de Rocío Silva, Pablo Giménez y José María Gómez entre otros.

El control de las aguas para el riego de los campos de cultivo implica comprender el espacio geográfico, analizar la hidrología, la topografía, la idoneidad de los suelos y, además, idear los artefactos oportunos que optimizan la gestión hídrica. Así, definimos un sistema de regadío como un espacio de gestión del agua articulado por una serie de artefactos y delimitado por las acequias que lo estructuran, las cuales se abastecen del agua que circula por el río, y que abarcan una superficie que varía en función de la naturaleza del terreno en el que se integran. Azudes, galerías drenantes pozos, acequias y canales, balsas y albercas, partidores, molinos, batanes etc. son algunos de los componentes de los sistemas de regadío tradicionales que además estructuran unos nuevos paisajes, impensables sin la intervención antrópica. Estamos ante una apertura de planteamientos de los objetos de estudio, mediante la consideración patrimonial de los regadíos tradicionales. Efectivamente, se tiende a una mayor apreciación del significado patrimonial de los espacios agrícolas irrigados. Se ha pasado del estudio del hito aislado a la valoración del conjunto, del sistema espacial y del paisaje. Se trata de un recorrido conceptual que ha permitido el reconocimiento patrimonial del legado de la agricultura (Silva, 2008).

Recientemente, los elementos de la arquitectura hídrica, así como la propia gestión tradicional del agua se han patrimonializado. Han adquirido un renovado valor entre científicos, así como entre importantes sectores de la sociedad, pues son una manifestación de la cultura sobre el territorio con repercusiones ecológicas y visuales, y por tanto paisajísticas (Iranzo, 2009). Son el resultado de un trabajo colectivo, que marcan una diferencia cultural específica. Tanto la dimensión espacial como la histórica tienen mucha relevancia en su configuración, ya que le confieren unas características genuinas que permiten la identificación de los distintos colectivos que lo han ido conformando y su distinción respecto a otros grupos sociales de hábitats diferentes. No obstante, este patrimonio de lo funcional es un patrimonio frágil, sometido a la problemática de su dispersión y de su progresivo deterioro por desuso.

Sin embargo, el análisis de los sistemas de regadío tradicionales desde una perspectiva paisajístico-patrimonial, pero también desde una perspectiva histórica o agronómica, necesita de unos trabajos previos, a veces infravalorados, de identificación, delimitación cartográfica y catalogación de los sistemas de riego y de los elementos que permiten su funcionamiento.

Resulta difícil analizar la dinámica de un sistema de riego, sin conocer las piezas que lo articulan y le permiten funcionar como una unidad. Así pues, el diseño e implementación de una base de datos espacial de los regadíos tradicionales es una tarea clave para poder investigar desde cualquier perspectiva o enfoque arriba citados. En este sentido la unidad de in- 
vestigación ESTEPA (Estudios del Territorio, Paisaje y Patrimonio) del Departament de Geografia de la Universitat de Valencia viene trabajando en los últimos años. La creación de un SIG con un método de caracterización y valoración de los regadíos tradicionales nos ha permitido, además de contar con la representación de la red de canales y acequias y con el inventario de los elementos del patrimonio del agua, efectuar análisis de la configuración y significado paisajístico de los regadíos, así como el valor patrimonial del conjunto.

Uno de los resultados de este macroproyecto de inventario del patrimonio del agua de los regadíos españoles, financiado por diversas instituciones como la Generalitat Valenciana, la Confederación Hidrográfica del Júcar o el Ministerio de Medio Ambiente, Medio Rural y Marino, nos está permitiendo llevar a cabo el análisis paisajístico-patrimonial de los regadíos del Turia. El río Turia es junto al Júcar el más emblemático de los ríos valencianos. Especialmente para aquellos que han vivido y viven junto a sus riberas, para los que el Turia representa un don en forma de vega fértil y huertas. El Turia se constituye como tal en el término municipal de Teruel, tras la confluencia de los ríos Alfambra y Guadalaviar. Avena una amplia extensión de territorio a su paso por tierras turolenses, conquenses y valencianas. En su recorrido hasta su desembocadura en el mar Mediterráneo, en Valencia, da lugar a una miríada de vegas irrigadas con las acequias que de él derivan por medio de azudes. Canales a los que se vinculan una amplia variedad de elementos hidráulicos (partidores, acueductos, sifones...), que con el tiempo se han patrimonializado. El Turia es un hidrosistema complejo. Un río anómalo como consecuencia de la evolución de red fluvial, caracterizada por el aumento superficial de la cuenca tras la captura por parte de un "modesto" río mediterráneo, de la fosa tectónica Turia-Alfambra (Pérez, 2008). Se trata de un curso fluvial de tipo mediterráneo que funciona de desagüe de los derrames de este sector de los relieves ibéricos.

Existen diferentes sectores de la cuenca del Turia que por sus características geomorfológicas e hidrológicas han posibilitado la configuración de espacios irrigados (figura 1). Aunque se han detectado pequeños sistemas de riego ligados a manantiales aledaños y a pequeños tributarios del cauce principal, en el trabajo que presentamos nos hemos ceñido a los ocho principales ambientes ribereños en los que el río ha edificado vegas aluviales. Se trata de la vega de Teruel, la vega de Ademuz, la pequeña vega de Santa Cruz de Moya, la pequeña vega del Molino del Marqués en Aras de los Olmos, la vega de Chulilla y la de Gestalgar, Bugarra y Pedralba, la vega de los "Pueblo-Castillo" en el Camp de Túria y finalmente del llano aluvial sobre el que se asienta l'Horta de València (figura 1). En todos estos espacios, el regadío se manifiesta mediante una red de acequias que teje a un parcelario agrícola de policultivos, jalonada por una serie de elementos que posibilitan la conducción y manejo del agua. La morfología del sistema de riego y la mayor o menor presencia de elementos del patrimonio del agua guarda relación con los rasgos geomorfológicos de la vega (amplitud y desnivel) y con los caudales disponibles. La pendiente es fundamental a la hora de explicar el trazado y la tipología de las acequias, pero también la tipología de los elementos del patrimonio hidráulico. Así pues, además de los elementos destinados a la captación (azudes), transporte (canales y acequias) y distribución (partidores), la complejidad del relieve o la irregularidad de caudales explica la presencia de elementos como los sifones, las escaleras, los acueductos o las balsas y albercas de acumulación.

Además de todo el patrimonio del agua material ligado a los sistemas de riego del río Turia y aunque no es objeto de análisis en la presente comunicación, existen otras modalidades de patrimonio del agua de tipo inmaterial relacionado con los conocimientos tradicionales para la gestión del agua, con el control jurídico de las aguas, así como otras manifestaciones en forma de folclore y toponimia. Todo ello no hace más que reforzar la idea de la pre- 
sencia de un rico y variado patrimonio, muchas de las veces desconocido o poco valorado y que está en un grave riesgo de desdibujarse irremediablemente.

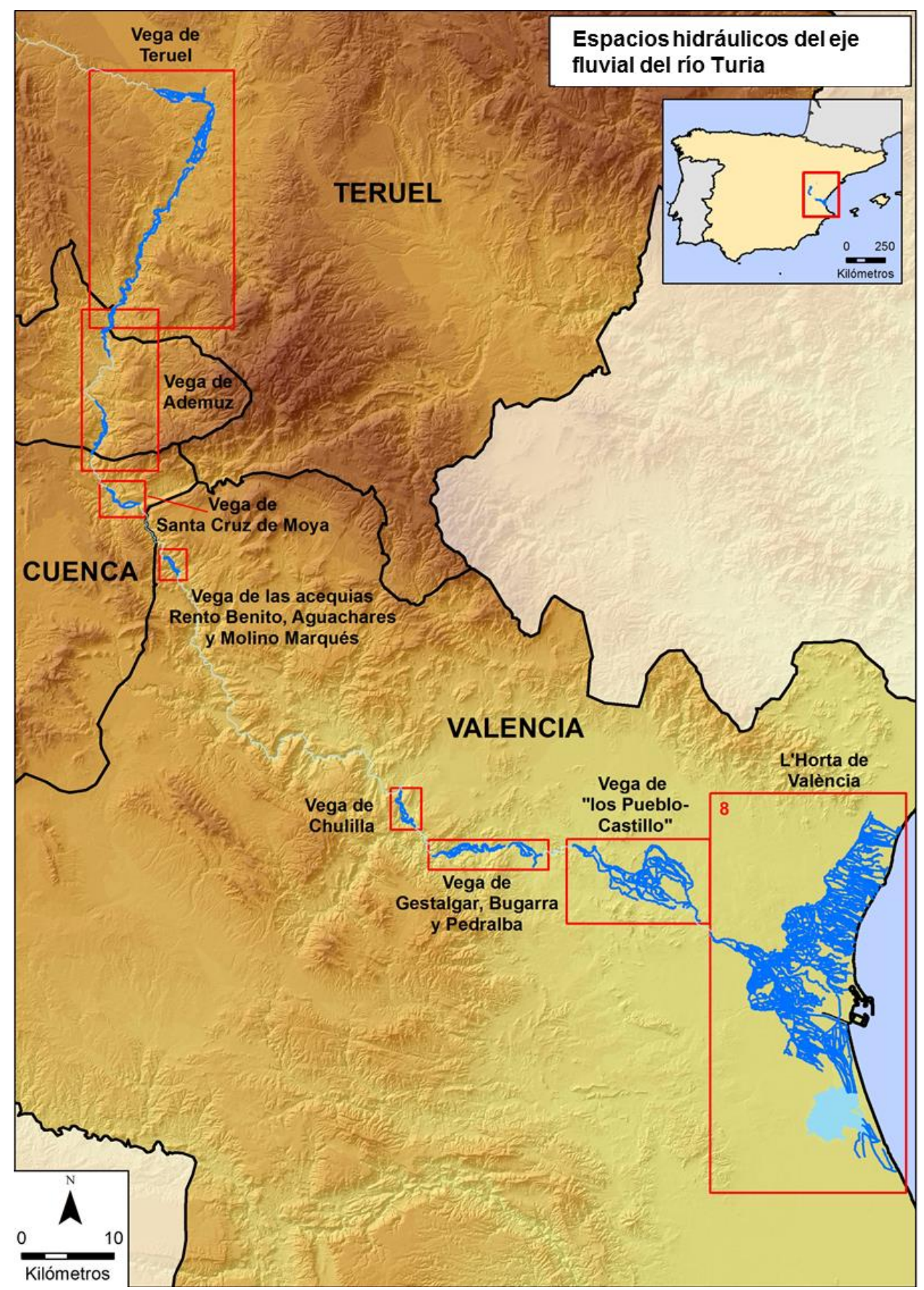

Fig. 1. Ambientes geomorfológicos y espacios hidráulicos del eje fluvial del Turia

\section{Justificación y objetivos}

En un momento como el actual donde el conocimiento tradicional se margina en pro de una racionalidad mal entendida en la que prima la eficiencia y el beneficio económico a 
corto plazo, los sistemas de regadío tradicionales caracterizados por la conducción del agua por gravedad y la irrigación a manta, se ven seriamente amenazados por diferentes motivos. Unos ligados al éxodo rural y al abandono generalizado de la actividad agrícola incapaz de generar rentas comparables a otro sectores y con altas exigencias de dedicación. Y otros ligados a la mecanización y tecnificación del campo, donde la búsqueda de la optimización de las explotaciones y el eterno problema de la escasez hídrica ha instado a la sustitución del riego a manta por otros métodos a priori más eficientes.

Pero, al margen del debate sobre la eficiencia y eficacia de los nuevos regadíos sobre los sistemas de riego tradicionales, lo que pretendemos dejar patente en este trabajo son los valores ambientales, históricos, culturales, paisajísticos..., en definitiva los valores patrimoniales que envuelven a los regadíos tradicionales. Unas estructuras que están en la base de muchos de los paisajes con los que convivimos cotidianamente y que nos generan bienestar y que, aunque estos espacios agrícolas y sus sistemas de riego están hoy relegados a un papel secundario dentro de la economía de mercado en la que estamos atrapados, podemos considerarlos como un recurso en estado latente, que ve como las trasformaciones de una sociedad "moderna" los va desdibujando.

Es por ello por lo que una investigación como la que se está llevando a cabo desde la unidad de investigación ESTEPA es oportuna y queda sobradamente justificada. Los sistemas de regadío tradicionales son un capital cada vez más ajeno y por tanto desconocido para la población que reside en las áreas metropolitanas. Un patrimonio que se desdibuja y que se nos escapa delante de nuestros ojos. Redescubrir los sistemas de regadío tradicionales, fijarlos aunque sea a través de documentos científicos es una responsabilidad que hemos decidido compartir con otros muchos colegas de la Geografía, la Historia, la Etnología, la Economía, el Derecho o la Ingeniería.

En la presente comunicación pretendemos caracterizar cuáles son los sistemas tradicionales de irrigación que a lo largo de la historia se han ido diseñando sobre los ocho principales ambientes ribereños edificados por el río Turia. Pero nuestro análisis no se reduce exclusivamente al inventario, siempre necesario, de acequias y elementos, sino que gracias al diseño de una infraestructura de datos espaciales manejada mediante el software ArcGIS hemos estudiado los rasgos definitorios de cada uno de los ochos sistemas identificados.

Así pues ante el doble objetivo de dar a conocer el inventario de los sistemas de regadío tradicionales y de los elementos del patrimonio del agua del eje fluvial del Turia catalogados, y de efectuar una caracterización (análisis morfológico y funcional por unidad hidráulica) y clasificación tipológica, se ha ensayado una descripción y clasificación de los sistemas en función de la superficie ocupada, la longitud de la red de acequias y canales y de la distribución y disposición de éstos por las riberas. También se presenta una jerarquización de las conducciones y su funcionalidad. Finalmente se valora el estado de conservación de los elementos de patrimonio hidráulico inventariado y se presentan los resultados de forma sintética.

\section{Materiales y métodos}

Para llevar a cabo este trabajo sobre los sistemas de regadío tradicionales del eje del río Turia, se han seguido varias etapas o fases. La primera fase de la investigación se ha centrado en la localización y recopilación de bibliografía, inventarios etnográficos y documentos digitales que constaten su presencia en las diferentes zonas tratadas. Entre los materia- 
les consultados destacan las obras de Pascual Madoz (Diccionario Geográfico-EstadísticoHistórico de España y sus posesiones de Ultramar, 1846-1850); de Antonio José Cavanilles (Las observaciones sobre la historia natural, geografía, agricultura, población y frutos del Reyno de Valencia, 1797) y del hidrólogo francés François Jaubert de Passa (Canales de riego de Cataluña y Reino de Valencia, leyes y costumbres que los rigen, reglamentos y ordenanzas de sus principales acequias, 1844). También se han consultado los diferentes Archivos Históricos Provinciales para las áreas consideradas. Con el conocimiento previo de la zona de estudio a través de las fuentes documentales se han visitado las diferentes Comunidades de Regantes con el fin de consultar las respectivas Ordenanzas de Regadío, las cuales aportan una información específica de los sistemas de regadío tradicional vinculados al territorio. Asimismo se han realizado entrevistas con los regantes y los técnicos locales con el fin de obtener información directa de los agentes territoriales.

Consultada la documentación escrita y oral, se analizan las diversas fuentes cartográficas como son el Catastro Topográfico Parcelario, escala 1:5.000, (cartografía catastral rústica 1930-1970); Planos Catastrales (1980-90) (cartografía catastral rústica 1980-1990); la cartografía del Institut Cartogràfic Valencià (ICV) a escala 1:10.000 y del Instituto Geográfico Nacional (IGN) a escala 1:25.000 y su Modelo Digital de Terreno, además de ortofotos de los diferentes organismos.

En una segunda etapa se coteja y se amplía "in situ" mediante el trabajo de campo, la información obtenida en la fase anterior. Para esta labor se intenta contactar con agentes locales especializados en el regadío tradicional. Para elaborar el catálogo e inventario del patrimonio del agua se recorren, de origen a fin, los sistemas de regadío tradicional. Esta tarea necesita del uso de instrumentos de geoposicionamiento GPS (Global Positioning Systems o Sistema de Posicionamiento Global) y de cartografía base. Por su parte, el inventario de los elementos hidráulicos, se complementa además de con referencias sobre su localización, con información acerca del estado de conservación, materiales de construcción, dimensiones, características singulares y un croquis, al tiempo que se realizan varias fotografías que suponen un aporte gráfico a la investigación. De esta forma se genera una base de datos georreferenciada de la cuenca del río Turia con los canales de riego y los elementos del patrimonio del agua, que registra sus características más relevantes.

En una tercera etapa, ya en el gabinete, se transfiere la información recogida en campo a un Sistema de Información Geográfica (SIG) sobre los regadíos históricos, en el que se digitalizan las acequias y elementos de regadío tradicional para la elaboración de cartografía temática. En dicho SIG se registran los datos básicos que hacen referencia a la denominación de la acequia; a la toma de la conducción principal; al nivel jerárquico del canal (si se trata de la acequia madre o de derivaciones que parten de la misma); a su estado de conservación; a su trazado (en descubierto o en subterráneo); a su funcionalidad (activa o inactiva); y a su longitud. En cuanto a los elementos del patrimonio hidráulico se incorpora al SIG su denominación, el municipio al que pertenece, su tipología (azud, balsa, noria, acueducto, motor...), estado de conservación y coordenadas UTM. Asimismo se realiza una catalogación de los elementos del patrimonio hidráulico.

Con el fin de conocer la superficie potencial irrigada de cada sistema se ha realizado una digitalización que toma cómo límites la acequia de mayor jerarquía que son aquellas que discurren a mayor cota en ambas márgenes del río. De ésta forma, se establece el perímetro de una zona que puede ser anegada con el recurso hídrico que fluye por las acequias. Finalmente, cabe señalar que además de ser un resultado del propio trabajo, la base de datos espacial SIG nos permite el tratamiento de la información obtenida abriendo la posibi- 
lidad de inferir posibles tendencias y situación de las conducciones y del patrimonio del agua.

\section{Resultados}

La información acumulada merced a las diferentes campañas de trabajo se ha centralizado en una base de datos espacial que nos ha permitido efectuar un análisis y caracterización de los principales espacios irrigados del eje principal del río Turia. Así pues, en el presente estudio se han identificado veintiún sistemas de irrigación diseñados sobre los ocho ambientes geomorfológicos de vega fluvial, con superficie suficiente como para convertirse en áreas agrícolas. El primero de los ambientes, siguiendo el sentido de las aguas, es la vega de Teruel, espacio de riego articulado mediante los tres sistemas de irrigación que se han identificado. El segundo ambiente es la vega de Ademuz, con dos sistemas de riego. El tercero está formado por la pequeña vega que edifica el río en Santa Cruz de Moya, donde sólo se ha identificado un sistema de riego. El cuarto ambiente o espacio agrícola de riego, es la vega conformada por las acequias de Rento Benito, Aguachares y Molino del Marqués, localizada en el término de Aras de los Olmos, que queda articulado por un único sistema; al igual sucede en el quinto ambiente conocido como la vega de Chulilla y en el sexto, la vega que forma el río entre Gestalgar, Bugarra y Pedralba. El séptimo ambiente, la vega de los "Pueblos Castillo" se configura a partir de, dos sistemas de riego y el octavo, el de L'Horta de València, gracias a diez.

\subsection{La Vega de Teruel}

El primer ambiente geomorfológico convertido en espacio agrícola irrigado es la vega de Teruel, donde los tres sistemas de riego que lo estructuran se extienden por una superficie de 1.244 hectáreas. El primero de ellos (en el sentido de las aguas) es el configurado por las acequias "madre o de primer nivel" (aquellas que derivan agua directamente desde el cauce del río), del Sargal, del Cubo y Valdeavellano (margen izquieda) y por la Acequia de Gea (margen derecha) que avenan el término municipal de Teruel. Atendiendo al área que irriga, en torno a las 336 ha, puede ser clasificado según Butzer (1989), como un sistema de mesosescala (250-1.500 ha) (Hermosilla, 2010). Por lo que respecta a la configuración morfológica del sistema de riego, el trazado de sus acequias genera una composición de valle de forma mural (Hermosilla y Peña, 2011). Éste se caracteriza por estar estructurado a través de una red de acequias principales que circulan en paralelo al río, y que se descomponen en otra red paralela secundaria con derivaciones perpendiculares que dirigen las aguas de riego hasta las explotaciones agrícolas. Posee una envergadura (suma de la longitud de las acequias de primer y segundo nivel que lo forman) de 25,920 kilómetros, de los cuales 21,905 se emplazan en la margen izquierda del Turia y 4,015 en la derecha. Como antes dejábamos entrever, existe una jerarquía en el conjunto de acequias y canales que lo estructuran, entendiendo por primer nivel jerárquico la acequia o canal con toma de agua directa desde el río. En este sentido, de las once que circulan por la izquierda, el 27\% (3) corresponde a acequias de primer nivel y el 73\% (8) de segundo. En el caso de la margen derecha, el 100\% (1) son de primer nivel, de los que surgen derivaciones perpendiculares encargadas del riego. Por lo que respecta a la funcionalidad del sistema de riego, en el momento en que se realizó el trabajo de campo, el 92\% de los canales estaban en uso, mientras que un 8\% habían dejado de ser utilizados. Si consideramos la funcionalidad por márgenes, la izquierda posee el $90 \%$ de los canales en uso. En el caso de la derecha, todas 
las conducciones cumplen con su cometido. Pero además de los canales y acequias, existen otros elementos y artefactos que forman parte del sistema de riego y que posibilitan su funcionamiento, que han sido analizados como parte del patrimonio del agua. Así pues, la funcionalidad de los elementos de patrimonio hidráulico catalogados asociados al sistema es del $65 \%$, mientras que un $35 \%$ está en desuso.

El segundo de los sistemas de la Vega de Teruel es conformado por las acequias de Argentera o del Molino Nuevo (margen izquierda) y del Guadalaviar y de la Peña (derecha) encargadas de irrigar Teruel y Villastar. Abarca una extensión 569 ha y como el anterior se trata de un sistema de mesoescala que dibuja una estructura de valle de morfología mural. La suma de la longitud de sus canales es de 52,830 km. De ellos el 30\% (15,775 km) se emplazan en la margen izquierda, y el $70 \%(37,055 \mathrm{~km})$ en la derecha. El 7\% (1) de las conducciones de la margen izquierda corresponden a una jerarquía de primer orden y el 93\% (13) de segundo. En el caso de la margen derecha, las proporciones son del 10\% (2) y el 90\% (18), respectivamente. En cuanto a la funcionalidad del sistema, el $98 \%$ de las canalizaciones del margen izquierdo del eje fluvial es funcional y sólo un 2\% han dejado de utilizarse. El canal de la margen derecha es $100 \%$ funcional. Como resultado del uso de las conducciones, el $84 \%$ de los elementos a ellas vinculados son funcionales, mientras que el $16 \%$ ha abandonado su cometido.

Finalmente, el tercer sistema compuesto por las acequias del Peñazo, del Campo y Ramblar (margen izquierda). Y acequia de las Masadas, del Molinar y de la Noguera en la opuesta, transcurren por339 ha repartidas entre los términos municipales de Villastar, Villel y Libros. Comparte características con los dos anteriores. Se trata de un sistema de mesoescala con una morfología mural, cuya envergadura es de 44,870 kilómetros de los cuales 13,430 circulan por la margen izquierda y 31,440 por la derecha a lo largo del eje fluvial. Al igual que en los casos anteriores, podemos observar el predominio de las acequias de segundo nivel (50\%, 3 canales en la margen izquierda y 77\%, 13 acequias en la derecha), mientras que las de primer nivel representan el 50\%, 3 acequias, en la margen izquierda y el $23 \%, 3$ acequias en la derecha. Su funcionalidad está garantizada pues prácticamente el 100\% están activas. Sólo un 5\% de las acequias del margen izquierdo no es funcional y un $1 \%$ ha desaparecido por su abandono. En el caso de la margen derecha el $1 \%$ no es funcional y otro $1 \%$ ha desaparecido. Al igual que en el segundo sistema, la mayor parte de sus elementos cumplen con su función $(86 \%)$.

En síntesis podemos señalar que en la vega de Teruel el 41\% de las acequias discurren por la margen izquierda y el 59\% por la derecha. Asimismo, como muestra de la estructuración de los sistemas vinculados a la vega, el 20\% (13) de los sistemas estudiados corresponde a canales de primer nivel y el 80\% (52) al segundo. La funcionalidad total del sistema es del 96\%. Las acequias desaparecidas por su abandono no llegan al 1\% del total. Este factor permite que el $80 \%$ de los elementos del patrimonio del agua estén activos y en un adecuado estado de conservación.

\subsection{La Vega de Ademuz}

El siguiente ambiente geomorfológico que abordaremos es el de la Vega de Ademuz, en el que los dos sistemas que lo componen cubren una superficie de 215 ha. Su envergadura alcanza los 19,309 kilómetros, todos ellos constituidos por acequias de primer nivel orden repartidas por igual entre ambas márgenes. El 86\% de las acequias o canales se hallan acti- 
vos y un $80 \%$ de los elementos vinculados a los sistemas también. El 14\% de los canales y el 20\% de los elementos, no son funcionales. Por sistemas, el más septentrional, es el formado por las acequias del Chopar, Prao Cura y de la Masada (margen derecha) y por la acequia Madre de Torrealta (margen izquierda). Se extiende por la vega entre los términos municipales de Castielfabib, Torrebaja y Ademuz ocupando una superficie de 129 hectáreas. En este sentido se ha clasificado como un sistema de pequeña escala (50-250 ha).

La estructura de la red de acequias hace que el sistema pueda ser tipificado como sistema de valle con morfología de peine. Se caracteriza por una pequeña red de acequias, en general de primer nivel, que circulan en paralelo al eje fluvial. De ella parten pequeñas conducciones, encargadas de la irrigación de los campos aledaños. En cuanto a sus características básicas podemos decir que, el 75\% (3) de los canales circulan por la margen derecha y el $25 \%$ (1) por la izquierda. El 100\% de las acequias del margen izquierdo son funcionales y el 94\% de las del derecho también, lo que indica que el sistema tiene un buen estado de salud en cuanto a su uso. Esto también se refleja en el estado de sus elementos que son funcionales al $100 \%$.

El segundo sistema de la vega de Ademuz, estructurado por las acequias de TablaoArenales, Umbría Negra y Sargalosa, por la margen izquierda, y por la Acequia del Molino, por la derecha, bonifica las localidades de Ademuz, Casas Altas y Casas Bajas. El sistema comparte las mismas características que el anterior, tanto en su estructura como en el hecho de ser un sistema de pequeña escala (85 ha). En este caso el 75\% (3) de las acequias fluyen por la margen izquierda y el 25\% (1) por la derecha, todos ellos de primer nivel. En este caso el $25 \%$ de la margen izquierda no son funcionales y el $12 \%$ en el lado contrario. Debido al abandono de las conducciones, en la actualidad el $25 \%$ de los elementos no están en uso.

\subsection{La Vega de Santa Cruz de Moya}

Aguas abajo, el siguiente espacio irrigado del eje del Turia es la pequeña Vega de Santa Cruz de Moya, en la provincia de Cuenca. Cuenta con una red de acequias que conforman un área de riego de una extensión de 102 hectáreas, por lo que ha sido clasificado como un sistema de pequeña escala. Su diseño responde a los sistemas de valle, concretamente a los de peine, al tratarse de una red de acequias pequeña paralela al eje fluvial, con pequeñas "regaderas" (pequeñas acequias) encargadas de la bonificación de los campos. Al igual que en el caso de la Vega de Ademuz, todos los canales identificados son acequias madre o de primer nivel. La envergadura del sistema es de 10,850 km, de los cuales el 18\% de las acequias se distribuyen por la margen izquierda, mientras que el $82 \%$ lo hacen por la derecha. Así pues, una sola acequia discurre por la margen izquierda, lo que supone el 16\% del sistema, mientras que son cinco, el $84 \%$ del conjunto, las que discurren por la margen contraria. En lo que se refiere al estado de salud del sistema, el $77 \%$ la acequia de la margen izquierda es funcional, frente al 95\% de las acequias de la margen derecha, en la que un 5\% se hallan desaparecidas. En síntesis se establece que el 91\% del sistema aún está en uso. En lo concerniente a sus elementos del patrimonio hidráulico, la mayor parte de ellos están activos y cumplen con su cometido. 


\subsection{La Vega del Molino del Marqués}

Ya en la comarca valenciana de la Serranía, emplazada en el sector suroccidental del término municipal de Aras de los Olmos, el Turia ha edificado una minúscula vega denominada del Molino del Marqués. En ella, un sistema de apenas 50 hectáreas, y por tanto clasificado como de microescala (Butzer, 1989; Hermosilla, 2010), estructura un enclavado paisaje del regadío. La disposición de la red de riego hace que podamos caracterizarlo como un sistema de valle de peine. Éste se estructura mediante las acequias de la Cueva de las Pedreras y la Rebollosa (margen derecha) y de Rento Benito, Aguachares y Molino Marqués (margen izquierda). Las acequias se extienden a lo largo de 5,900 kilómetros. Todas ellas son de primer orden repartidas casi por igual (52 y 48\%) entre ambas márgenes. En este caso el tratarse de un espacio agrícola de escasas dimensiones, productividad limitada y el hecho de que se halle ubicado en una zona alejada de los núcleos de población explica el parcial abandono del sistema, donde el 100\% de las conducciones de la margen derecha ya no son funcionales. Algo similar $(92 \%)$ sucede en la margen contraria, razón por la cual el $100 \%$ de los elementos vinculados al sistema ya no cumplen con su cometido.

\subsection{La Vega de Chulilla}

La Vega de Chulilla, cuyo sistema de riego de unas 100 hectáreas y por tanto de pequeña escala, queda configurado por las acequias de los Huertos, Vallfiguera, Larilla y Borche (margen derecha) y Acequia de Tras Castillo, Par de Molinos, Maté, Arca Mayor, Mira de Arriba y Mira Abajo (margen izquierda). Tiene una envergadura de 11,205 km (60\% margen derecha y $40 \%$ izquierda) y, al igual que el caso anterior, se trata de un sistema de valle de peine. En la actualidad el sistema se articula en torno a dos acequias, una por cada margen, funcionales en la mitad de su trazado respectivamente. El resto de las acequias se hallan en desuso debido al abandono de los campos asociados a las canalizaciones. No obstante, el 100\% de los elementos inventariados cumple con su cometido.

\subsection{La Vega de Gestalgar-Pedralba}

La vega más meridional del río Turia en la comarca de la Serranía es la de GestalgarPedralba, que se extiende por 450 hectáreas entre las localidades de Gestalgar, Bugarra y Pedralba. La disposición de las acequias configura un sistema de riego del tipo de valle, escalonado, al poseer una red de acequias paralela significativa. El sistema queda estructurado por las acequias del Rajolar, Rincón, Huerta Nueva y Segontín, del Olivar, de las Suertes, de la Rambla Tomás, del Higueral, de Dalt, de Baix, de la Rambla de los Pérez, del Llano Puente, del Chorret y de la Plana en la margen derecha. Y Acequia de Lugar (Gestalgar), de la Ermita, Zapatería y de Cueva Paulo, de Caravinas, del Lugar (Bugarra) Mayor de Pedralba, de la Horteta y Acequia de la Huerta de Arriba en la margen opuesta. Entre ambas márgenes se reparten dieciocho acequias (siete en la izquierda, el $40 \%$ y once en la derecha, el 60\%), todas ellas de primer orden que suman en total una longitud de 32,015 kilómetros de los cuales el $46 \%$ discurren por la izquierda y el $54 \%$ por la derecha. En ésta vega, a diferencia de las dos anteriores, el 90\% de las acequias son funcionales, siendo este valor similar en ambas riberas. De su estado de salud deriva que el $85 \%$ de los elementos del patrimonio del agua se hallan operativos y en buen estado de conservación. 
Si consideramos los tres sistemas de las tres vegas de la Serranía en conjunto se observa que todas las acequias son de primer nivel y que, el total de sus kilómetros (49,161 km) se reparten por igual entre ambas riberas. Similar es en lo que se refiere al número de acequias. Nueve en la izquierda $(40 \%)$ y trece en la derecha $(60 \%)$. Cerca de una cuarta parte de las acequias de los sistemas $(26 \%)$ no están en uso en la actualidad por el abandono de la actividad agrícola. Este abandono se refleja en que el 15\% de los elementos del patrimonio del agua no están operativos.

\subsection{La Vega de los Pueblos Castillo}

El penúltimo ambiente sedimentario creado por el Turia sobre el que se ha construido un importante espacio hidráulico que utiliza sus aguas para alumbrar a los cultivos, es la vega de los "Pueblos Castillo" (figura 2). En ella se han identificado dos sistemas de riego. El de la margen derecha comprende una superficie de 775 hectáreas, entre los términos municipales de Vilamarxant y Riba-roja de Túria y queda articulado por las acequias Major de Vilamarxant, Riba-roja de Túria y el Roll de Rosser. El sistema de la margen izquierda se extiende por 3.060 hectáreas repartidas en los términos municipales de Benaguasil, la Pobla de Vallbona, l'Eliana y Riba-roja de Túria, siendo las acequias de primer orden de Benaguasil, Major, Nova (colector de Benaguasil), Granotera (colector de la Pobla de Vallbona), del Mandor, de Lorca o de Riba-roja y la de la Vallesa la que lo estructuran. Entre ambos sistemas cubren una superficie de 3.835 ha con una longitud total de sus canalizaciones de 130.160 kilómetros.

Analizando el sistema de cada margen por separado podemos confirmar que el de la margen derecha se clasifica como de mesoescala (250-1.500 ha) con una estructura de valle de morfología mural. La envergadura de este sistema es de $28,270 \mathrm{~km}$. canalizaciones repartidos entre tres acequias principales (de primer nivel) y cinco de segundo nivel. La funcionalidad de las conducciones es del $90 \%$, lo que indica un buen estado de salud, si bien es cierto que sólo el $54 \%$ de los elementos del patrimonio hidráulico vinculados al sistema son funcionales. Esto se debe, en parte a que algunos elementos, como molinos, lavaderos y abrevaderos, ya no cumplen con su cometido.

El sistema de la margen izquierda comparte características morfológicas con el de la derecha, si bien es cierto que tiene una mayor envergadura. Su extensión superficial hace que lo clasifiquemos, dentro de los sistemas medianos, como de escala intermedia (Hermosilla, 2010). Sus canalizaciones se extienden a lo largo de 101,890 km repartidos en 26 acequias. De ellas, el 27\% (7) son de primer nivel; el 66\% (17) de segundo y el 7\% (2) de tercer nivel. Esta jerarquización de la red configura un sistema de riego más complejo. Del conjunto de canales y acequias sólo el 2,5\% han dejado de ser funcionales o han desaparecido. 


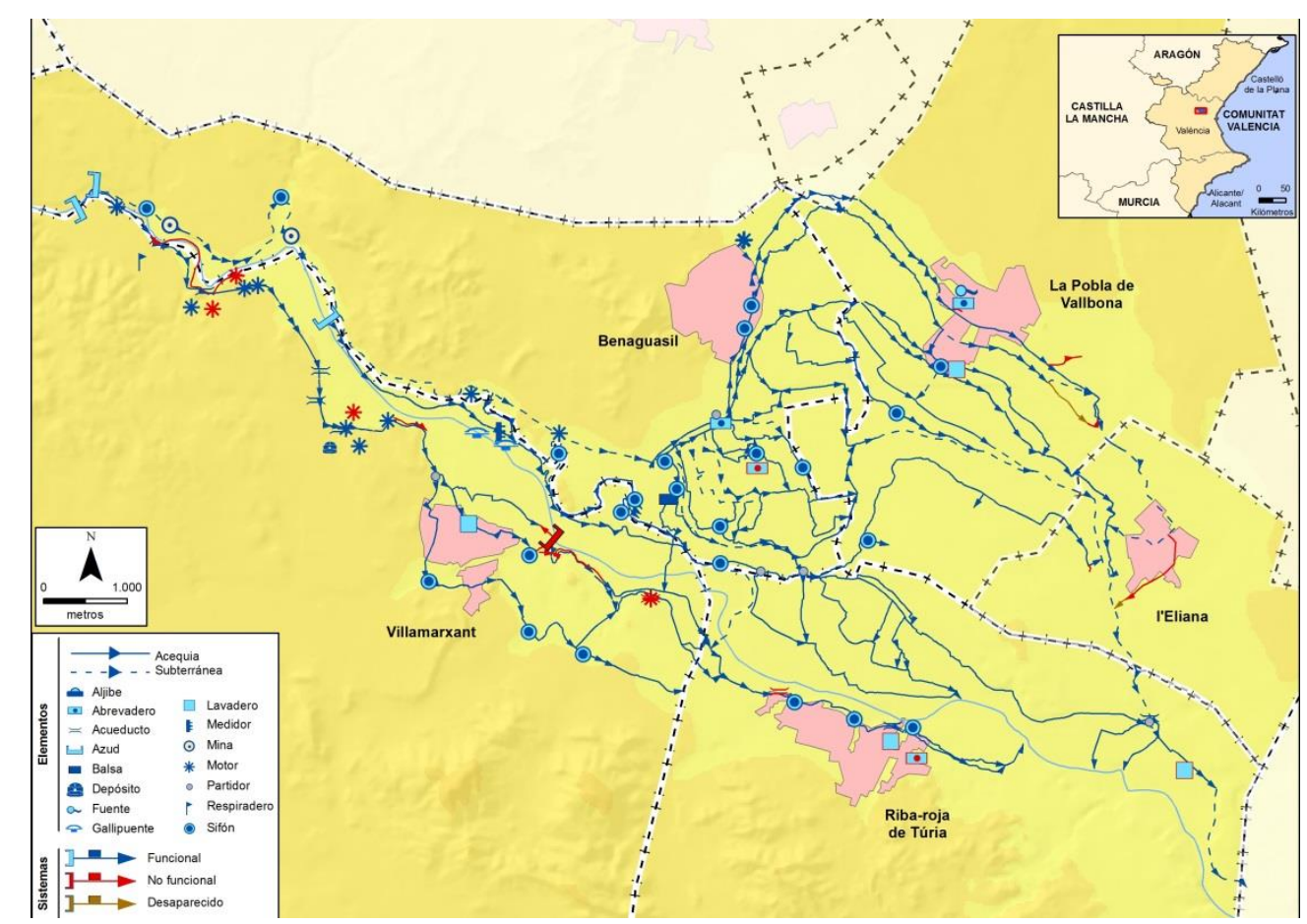

Fig. 2. Sistemas de riego y elementos del patrimonio hidráulico de la vega de los Pueblo Castillo

\subsection{L'Horta de València}

El ambiente sedimentario más próximo a la desembocadura que ha edificado el río Turia es la llanura aluvial de Valencia. En este espacio se han conjugado una serie de factores geográficos (abundante espacio llano y fértil, disponibilidad de agua, clima favorable y presencia de núcleos de población) que explican la creación del más extenso y reconocido espacio hidráulico del Turia: l'Horta de València. Con sus 12.905 hectáreas este sistema de sistemas se clasifica como de macroescala (5.000-20.000 ha). Es irrigado por diez acequias o canales (entre acequias históricas y otros canales) que por sus complejas ramificaciones son consideradas cada una de ellas como un propio sistema. Nos referimos a las acequias del Canal de Daroqui, Manises, Quart, Benager (Rollet d'Aldaia) y Faitanar (margen derecha del río Túria); al Canal de Riego del río Turia (margen derecha); a los Canales de l'Albufera (margen derecha), que aunque no toman directamente del eje principal, reciben los excedentes de conducciones que sí que lo hacen; la Reial Séquia de Montcada (margen izquierda); la Séquia de Favara (margen derecha); la Séquia de Mestalla (margen izquieda); la Séquia de Mislata (margen derecha); la Séquia de Rascanya (margen izquierda); la Séquia de Rovella (margen derecha) y la Séquia de Tormos (margen izquierda). Entre las acequias de primer, segundo y tercer nivel de los diez sistemas se cubre una longitud de 392,268 kilómetros repartida casi al 50\% entre ambas márgenes (Tabla 1). 
Tabla 1. Envergadura de los sistemas de riego de l'Horta de Valencia (acequias principales)

\begin{tabular}{|c|c|c|c|c|c|c|c|c|}
\hline Nombre del sistema & Margen & $\begin{array}{l}\mathrm{Km} \\
\text { totales }\end{array}$ & $\begin{array}{l}\text { Km de } \\
\text { nivel } 1\end{array}$ & $\%$ & $\begin{array}{r}\text { Km de } \\
\text { nivel2 }\end{array}$ & $\%$ & $\begin{array}{l}\text { Km de } \\
\text { nivel } 3\end{array}$ & $\%$ \\
\hline \multicolumn{9}{|l|}{ Canal de Daroqui, Manises, } \\
\hline Quart, Benager y Faitanar. & Dcha & 49,9 & 5,2 & 10 & 15,8 & 32 & 28,9 & 58 \\
\hline Canal del río Túria & Izq & 74,3 & 14,1 & 19 & 46,4 & 62 & 13,8 & 19 \\
\hline Canales de l'Albufera & Dcha & 3,1 & 3,1 & 100 & 0 & 0 & 0 & 0 \\
\hline Reial Séquiade Montcada & Izq & 134,5 & 33,4 & 25 & 91,8 & 68 & 9,3 & 7 \\
\hline Séquia de Favara & Dcha & 44,7 & 0,4 & 1 & 14 & 31 & 30,3 & 68 \\
\hline Séquia de Mestalla & Izq & 19,4 & 3,8 & 20 & 15,6 & 80 & 0 & 0 \\
\hline Séquia de Mislata & Dcha & 19,5 & 3 & 15 & 6 & 31 & 10,5 & 54 \\
\hline Séquia de Rascanya & Izq & 18,5 & 9,6 & 52 & 8,9 & 48 & 0 & 0 \\
\hline Séquia de Rovella & Dcha & 10,2 & 10,2 & 100 & 0 & 0 & 0 & 0 \\
\hline Séquia de Tormos & Izq & 18,3 & 5,9 & 32 & 5,5 & 30 & 6,9 & 38 \\
\hline TOTAL Izquierda-Derecha & & 392,4 & 88,7 & 23 & 204 & 52 & 99,7 & 25 \\
\hline
\end{tabular}

Tabla 2. Número de sistemas y subsistemas por niveles jerárquicos de l'Horta de València

\begin{tabular}{cccccccc}
\hline Nombre del sistema & $\begin{array}{c}\mathbf{N}^{\mathbf{0}} \\
\text { subsistemas }\end{array}$ & Nivel 1 & $\mathbf{\%}$ & $\begin{array}{c}\text { Nivel } \\
\mathbf{2}\end{array}$ & $\mathbf{\%}$ & Nivel 3 & $\mathbf{\%}$ \\
\hline $\begin{array}{c}\text { Canal de Daroqui, Ma- } \\
\text { nises, Quart, Benager y } \\
\text { Faitanar }\end{array}$ & 22 & 1 & 5 & 6 & 27 & 15 & 68 \\
$\begin{array}{c}\text { Canal del río Túria } \\
\text { Canales de l'Albufera }\end{array}$ & 12 & 1 & 8 & 8 & 67 & 3 & 25 \\
Reial Séquia de Mont- & 1 & 1 & 100 & 0 & 0 & 0 & 0 \\
$\begin{array}{c}\text { cada } \\
\text { Séquia de Favara }\end{array}$ & 33 & 1 & 3 & 29 & 88 & 3 & 9 \\
Séquia de Mestalla & 13 & 1 & 8 & 2 & 15 & 10 & 77 \\
Séquia de Mislata & 4 & 1 & 25 & 3 & 75 & 0 & 0 \\
Séquia de Rascanya & 7 & 1 & 14 & 2 & 29 & 4 & 57 \\
Séquia de Rovella & 5 & 1 & 20 & 4 & 80 & 0 & 0 \\
Séquia de Tormos & 1 & 1 & 100 & 0 & 0 & 0 & 0 \\
\hline TOTAL & 6 & 1 & 17 & 3 & 50 & 2 & 33 \\
\hline
\end{tabular}

Su estructura morfológica es propia de los sistemas de llanura de inundación. Analizando la red de riego de l'Horta 10 acequias (10\% del total) son de primer nivel; el 55\% (57 acequias menores y brazales) son de segundo nivel y el 35\% (37 ramales) al tercero (tabla 2). Las conducciones de primer nivel cumplen con una función de transporte del agua desde 
el cauce del río hasta el espacio irrigado, mientras que las de segundo y tercer nivel (y sus respectivas ramificaciones, cómo los niveles 4, 5 y 6 que se dan en l'Horta) son las encargadas de repartir el agua por los campos de cultivo.

En lo concerniente a la funcionalidad del sistema, el 92\% del total de las conducciones cumplen con su finalidad, el $4 \%$ no están en uso y el $4 \%$ han desaparecido (tabla 3). El sistema muestra del buen estado de salud de las acequias que avenan L'Horta de València y el $85 \%$ de los elementos catalogados están en uso y en buen estado de conservación (tabla 4).

Tabla 3. Funcionalidad de la totalidad de canales y acequias de l'Horta de V alència

\begin{tabular}{lccccccc}
\hline Nombre del sistema & $\begin{array}{c}\text { Km total } \\
\text { acequias }\end{array}$ & $\begin{array}{l}\text { Km aceq. } \\
\text { funcionales }\end{array}$ & $\begin{array}{c}\text { Km no } \\
\text { funcionales }\end{array}$ & $\%$ & $\begin{array}{c}\text { Km acequias } \\
\text { desaparecidas }\end{array}$ & $\%$ \\
\hline Canal de Daroqui, Manises, & & & & & & & \\
Quart, Benagery Faitanar & 119,5 & 109,6 & 92 & 3,1 & 2 & 6,8 & 6 \\
Canal del rí Túria & 87,9 & 81,6 & 93 & 2,8 & 3 & 3,5 & 4 \\
Canales de l'Albufera & 22,6 & 22,6 & 100 & 0 & 0 & 0 & 0 \\
Reial Séquia de Montcada & 353,1 & 342,2 & 97 & 4,8 & 1 & 6,1 & 2 \\
Séquia de Favara & 126,1 & 116 & 92 & 1,1 & 1 & 9 & 7 \\
Séquia de Mestalla & 63,2 & 43,8 & 69 & 17,9 & 28 & 1,5 & 2 \\
Séquia de Mislata & 58,2 & 41,6 & 71 & 0 & 0 & 16,6 & 29 \\
Séquia de Rascanya & 72,9 & 69,9 & 96 & 3 & 4 & 0 & 0 \\
Séquia de Rovella & 10,4 & 10,4 & 100 & 0 & 0 & 0 & 0 \\
Séquia de Tormos & 71,3 & 66,4 & 93 & 4,6 & 6 & 0,3 & 1 \\
\hline \multicolumn{1}{c}{ TOTAL } & $\mathbf{9 8 5 , 2}$ & $\mathbf{9 0 4 , 1}$ & $\mathbf{9 2}$ & $\mathbf{3 7 , 3}$ & $\mathbf{4}$ & $\mathbf{4 3 , 8}$ & $\mathbf{4}$ \\
\hline
\end{tabular}

Tabla 4. Funcionalidad de los elementos del patrimonio del agua de l'Horta de València

\begin{tabular}{cccccc}
\hline Nombre del sistema & $\begin{array}{c}\mathbf{N}^{\mathbf{o}} \text { de ele- } \\
\text { mentos }\end{array}$ & Funcionales & $\mathbf{\%}$ & No funcionales & $\mathbf{\%}$ \\
\hline Canal de Daroqui, Manises, & 40 & 34 & 85 & 6 & 15 \\
Quart, Benager y Faitanar & 16 & 9 & 56 & 7 & 44 \\
Canal del río Túria & 9 & 9 & 100 & 0 & 0 \\
Canales de l'Albufera & 104 & 93 & 89 & 11 & 11 \\
Reial Séquia de Montcada & 19 & 13 & 68 & 6 & 32 \\
Séquia de Favara & 2 & 2 & 100 & 0 & 0 \\
Séquia de Mestalla & 7 & 6 & 86 & 1 & 14 \\
Séquia de Mislata & 10 & 10 & 100 & 0 & 0 \\
Séquia de Rascanya & 2 & 1 & 50 & 1 & 50 \\
Séquia de Rovella & 7 & 7 & 100 & 0 & 0 \\
Séquia de Tormos & $\mathbf{7 1 6}$ & $\mathbf{1 8 4}$ & $\mathbf{8 5}$ & $\mathbf{3 2}$ & $\mathbf{1 5}$ \\
\hline TOTAL & & & &
\end{tabular}




\section{Discusión y conclusiones}

El análisis llevado a cabo nos ha permitido caracterizar los espacios agrícolas y sistemas de regadío de los ocho ambientes sedimentarios del río Turia. De los 731.7 kilómetros de conducciones de primer, segundo y tercer nivel repartidos, por ambas márgenes del eje fluvial (48\% de los kilómetros discurren por la margen derecha y el 52\% por la opuesta), el $41 \%$ corresponde a acequias de primer orden, el $45 \%$ al segundo y el $14 \%$ al tercero. De las 239 conducciones identificadas y cartografiadas que articulan los ocho espacios hidráulicos, el 29\% (69) son de primer nivel, 55\% (131) de segundo y 16\% (39) de tercero. En los sistemas de pequeña escala la red de acequias es generalmente simple, con predominio de las acequias de primer orden que abastecen a las regaderas que alumbran las parcelas, $\mathrm{o}$ que incluso riegan ellas directamente los campos. Sin embargo allí donde los espacios hidráulicos son más extensos, los sistemas se tornan más complejos. Ejemplo de ello son las vegas de Teruel, de los Pueblos Castillo o l'Horta de Valencia, donde el predominio de las conducciones de segundo nivel nos indica que se tratan de espacios hidráulicos complejos y antiguos. En el caso de los dos últimos se reparten el $72 \%$ de los kilómetros de canales y acequias identificados para el conjunto de las 8 vegas y el 58\% de los sistemas que las articulan. Tanto la vega de los Pueblos Castillo como l'Horta constituyen los espacios más complejos de los estudiados.

En lo que se refiere a la funcionalidad de los sistemas estructurantes de los espacios irrigados, el 92\% del total de las conducciones son funcionales (se incluyen todos los canales que configuran los sistemas sin hacer distinción de jerarquía). El 5\% no es funcional y el $2 \%$ ha desaparecido debido al abandono de los campos de cultivo. Sin embargo estos datos no nos deben confundir y hacernos pensar que los sistemas de riego tradicionales están exentos de peligro. Muchas acequias y canales se mantienen activas gracias al cuidado de unas comunidades de regantes cada vez con menos miembros. Sin embargo el trabajo de campo nos muestra el incremento de las parcelas abandonadas. La funcionalidad y estado de conservación de los elementos del patrimonio del agua también se han considerado en la caracterización de los sistemas. De la totalidad de los inventariados el 82\% aún cumple con su cometido, mientras que el 18\% ha dejado de estar funcionales.

La preservación de los regadíos tradicionales como un patrimonio y un paisaje cultural precisa de la adopción de medidas y la adaptación de la actividad agrícola que los sustenta. Es posible que las dinámicas socioeconómicas actuales nos conduzcan al abandono de algunos sistemas que hoy día han quedado descontextualizados. Sin embargo aún son numerosos los espacios agrícolas de regadío que tratan de perdurar, pero que se ven continuamente amenazados por la sombra de una agricultura con problemas para competir en el mercado global, de los crecimientos urbanos sobre los espacios más fértiles y llanos, y por la reconversión a sistemas de irrigación más eficientes. Existen trabajos (Hermosilla y Peña, 2013) que abogan por repensar el papel de estos espacios hidráulicos tradicionales; trabajos que apuntan políticas que garanticen el conocimiento real de los regadíos mediante ejercicios de inventario, análisis y evaluación, como el que aquí presentamos, con el fin de diseñar las oportunas medidas de protección, conservación y puesta en valor del patrimonio hidráulico. 


\section{Referencias}

Butzer, K.W. (et al.)(1989): Orígenes de la distribución intercomunitaria del agua en la Sierra de Espadá. Los paisajes del Agua. Libro jubilar dedicado al profesor Antonio López Gómez. València: Universitat de València-Universitat de Alicante.

Cavanilles, A. J. (1795-1797): Observaciones sobre la historia natural, geografía, agricultu-ra, población y frutos del Reyno de Valencia. Reproducción Facsímil. Ediciones Albatros, València, 1985. 2 Vols.

Glick, T.F. (2007): Paisajes de conquista. Cambio cultural y geográfico en la España medieval, Valencia, Universitat.

Hermosilla, J. (2010): Los regadíos históricos españoles: paisajes culturales, paisajes soste-nibles. Colección gestión tradicional del agua, patrimonio cultural y sostenibilidad, n⿳3. Madrid. Ministerio de Medio Ambiente y Medio Rural y Marino.

Hermosilla, J. (dir.) (2007): El patrimonio bidráulico del Bajo Turia: L'Horta de València. Colección Regadíos Históricos Valencianos, Nº9. Valencia, Direcció General de Patrimoni Cultural Valencià .Generalitat Valenciana.

Hermosilla, J. (dir.) (2008): Las vegas tradicionales del Alto Turia: sistemas y paisajes. Co-lección Regadíos Históricos Valencianos, No10. Valencia, Direcció General de Patrimoni Cultural Valencià y Universitat de València

Hermosilla, J. (dir.) (2009): Los regadíos históricos del Turia Medio: la Serranía y el Camp de Túria, Colección Regadíos Históricos Valencianos, Nº11. Valencia, Direcció General de Patrimoni Cultural Valencià y Universitat de València.

Hermosilla, J.; Peña, M. (2013): "La arquitectura hidráulica de los regadíos históricos valencianos. Claves territoriales y tipologías en torno a sus elementos, redes y sistemas" en Biblio $3 W$. Revista bibliográfica de Geografía y Ciencias Sociales Vol XVIII, núm 1024. Universitat de Barcelona.

Iranzo, E. (2009): El paisaje como patrimonio rural. Propuesta de una sistemática integrada para el análisis de los paisajes valencianos. Tesis doctoral. Servei de Publicacions de la Universitat de Valencia.

Jaubert de Passa, F. (1844): Canales de riego de Cataluña y reino de V alencia, leyes y cos-tumbres que los rigen, reglamentos y ordenanzas de sus principales acequias. Imp. B. Monfort, Valencia, 1991. 2 Vols.

Madoz, P. (1845): Diccionario Geográfico-Estadístico-Histórico de Alicante, Castellón y Valencia. Edición Facsímil. Institució Alfons el Magnànim, Valencia, 1982. 2 Vols.

Pérez, A. (2008) Medio físico y regadíos fluviales en el Alto Turia Turolense, en Hermosilla, J., Las vegas tradicionales del Alto Turia: sistemas y paisajes de regadio. Colección re-gadíos Históricos Valencianos, No10, Direcció General de Patrimonio Cultural Valencià y Universitat de València.

Sanchis, C, Hermosilla, J. e Iranzo, E. (2004): Entorn al patrimoni hidràulic del regadiu històric valencià, Saitabi 54, pp. 223-234.

Silva, R. (2008): Hacia una valoración patrimonial de la agricultura, Scripta Nova. Revista electrónica de Geografía y Ciencias Sociales Vol. XII, núm. 275. Universitat de Barcelona. 